\title{
Midline intracranial cysts in identical twin brothers
}

\author{
R. Shane Tubbs ${ }^{1}$, W. Jerry Oakes ${ }^{2}$, John C. Wellons ${ }^{2}$ \\ ${ }^{1}$ Department of Cell Biology, University of Alabama at Birmingham, Alabama, U.S.A. \\ ${ }^{2}$ Department of Pediatric Neurosurgery, Children's Hospital, Birmingham, Alabama, U.S.A.
}

\begin{abstract}
Midline cysts of the anterior brain are common in infants e.g. cavum septum pellucidum et vergae. We report twin brothers with midline intracranial cysts, mildly increased ventricular size, and macrocephaly. One brother had a cavum septum pellucidum and vergae and the other a cavum septum pellucidum. With the obliteration of each brother's midline cyst the head circumference was noted to return to a normal head circumference curve and the ventricles decreased in size. We hypothesize that in infancy some cases of infantile macrocephaly are induced by a midline cyst and that as the cyst obliterates that physiologic cerebrospinal fluid pathways are established so that the head circumference returns within normal parameters. This knowledge should be kept in mind by the clinician who may wish to surgically intervene with a midline cyst prior to it demonstrating its natural history. Moreover, these data should especially be entertained in the premature infant. (J Pediatr Neurol 2004; 2(2): 107-110).
\end{abstract}

Key words: siblings, midline cysts, brain, cerebrospinal fluid, hydrocephalus.

\section{Introduction}

Anterior midline intracranial cysts may be found primarily in three forms: cavum septum pellucidum, cavum vergae, and cavum veli interpositum. Most of these fluid collections are benign and disappear

Correspondence: R. Shane Tubbs, Ph.D.,

Pediatric Neurosurgery 1600 7th Avenue South Acc 400

Birmingham, Alabama 35233 U.S.A.

Tel: 205-939-9914, fax: 205-939-9972.

E-mail: richard.tubbs@ccc.uab.edu

Received: November 05, 2003

Revised: November 15, 2003.

Accepted: November 19, 2003. with time with no consequence; however, some patients may have associations or potentially become symptomatic due to the mass effect of these cavities $(1,2)$. We report twin brothers each with a congenital midline intracranial cyst and macrocephaly who were otherwise asymptomatic.

\section{Case Reports}

Case 1

This is an ex 30 week premature male with grade I intraventricular hemorrhage (IVH). This child was in intensive care for approximately one month and ventilated for two days. At 2.5-monthold the child's head circumference was $38 \mathrm{~cm}\left(>98^{\text {th }}\right.$ percentile for adjusted age). An outside hospital's ultrasound of the head suggested a grade I or II IVH. Unenhanced head computerized tomography (CT) revealed mildly dilated ventricular size and cavum septum pellucidum and vergae (Figure 1). No other intracranial anomalies were found. This child's physical examination was within normal limits, however, the anterior fontanelle was full but not tense. There were no birth marks noted in this patient. Developmental milestones were being met. Three months later, the anterior fontanelle remained full and the head fell to the $95^{\text {th }}$ percentile for adjusted age at $44 \mathrm{~cm}$. At seven months of age the child's head circumference was $45.5 \mathrm{~cm}$ and had fallen to the $90^{\text {th }}$ percentile. A repeat head CT was performed which showed obliteration of the cavum vergae, decreased ventricular size, and residual cavum septum pellucidum (Figure 2).

\section{Case 2}

This is the younger identical twin brother of Case 1. A similar presentation was seen in this patient who presented with a head circumference of $37.5 \mathrm{~cm}$ and a full anterior fontanelle. His head circumference adjusted for prematurity was plotted near the $98^{\text {th }}$ percentile for age. Imaging from an outside institution suggested a low-grade intraventricular hemorrhage. Once imaged at our institution, ventricles were found to be slightly enlarged and there was a cavum septum pellucidum 


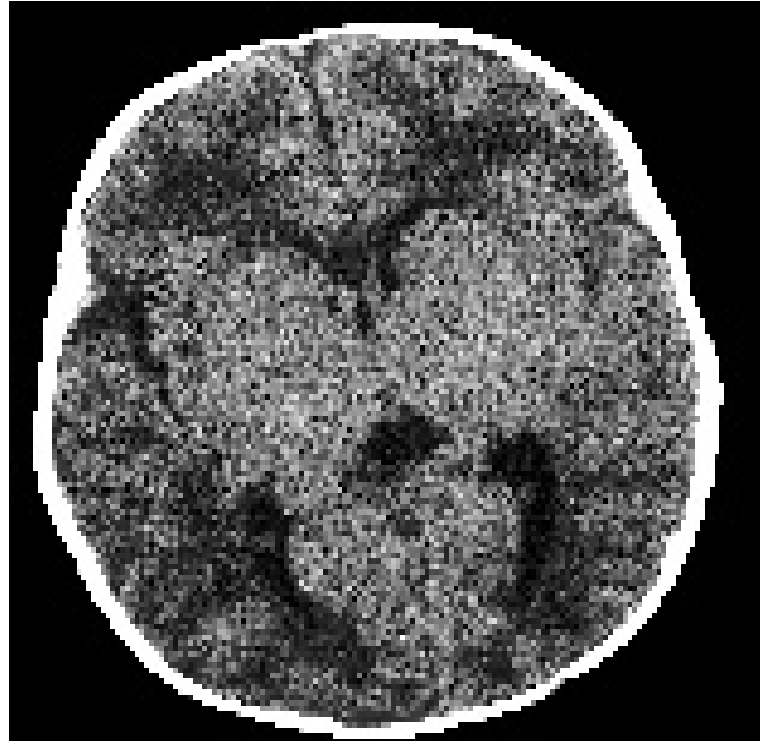

Figure 1. Head CT of Case 1 demonstrating both cavum septum pellucidum and vergae and slightly dilated ventricles

noted (Figure 3). No other intracranial anomalies were observed. Physical examination other than a large head and full anterior fontanelle was unremarkable. At 11 months old the patient returned with a head circumference of $47.5 \mathrm{~cm}$ which plotted at the $95^{\text {th }}$ percentile for adjusted age. A head CT demonstrated near resolution of the cavum septum pellucidum and decreased ventricular size (Figure 4). Developmental milestones were being met at his most recent clinic visit.

\section{Discussion}

Cavum septi pellucidi as the other cysts in this discussion, are not lined with ependyma and, therefore, do not produce cerebrospinal fluid (3). These cysts first described in the 1600's are noted in the $110 \mathrm{~mm}$ crown-rump human embryo (3). This "fifth ventricle" lies between the leaflets of the septum pellucidum and normally collapses in the perinatal period once the fluid within its walls is absorbed (4). Because of the enormous growth of the corpus callosum in the anteroposterior direction, the commissural plate between the anterior commissure, hippocampal commissure, and corpus callosum is progressively stretched to become the septum pellucidum. The potential space within the leaflets is termed the cavum septum pellucidum. It has been found that only $15 \%$ of infants will maintain this structure by 6 months of age (3). Interestingly, pugilists have an increased incidence of these cysts (3). In a literature review, multiple associations have been found with this form of midline cerebral cyst including: seizures, dementia, headache, hemiparesis, developmental defects, and psychosis. However, some have found

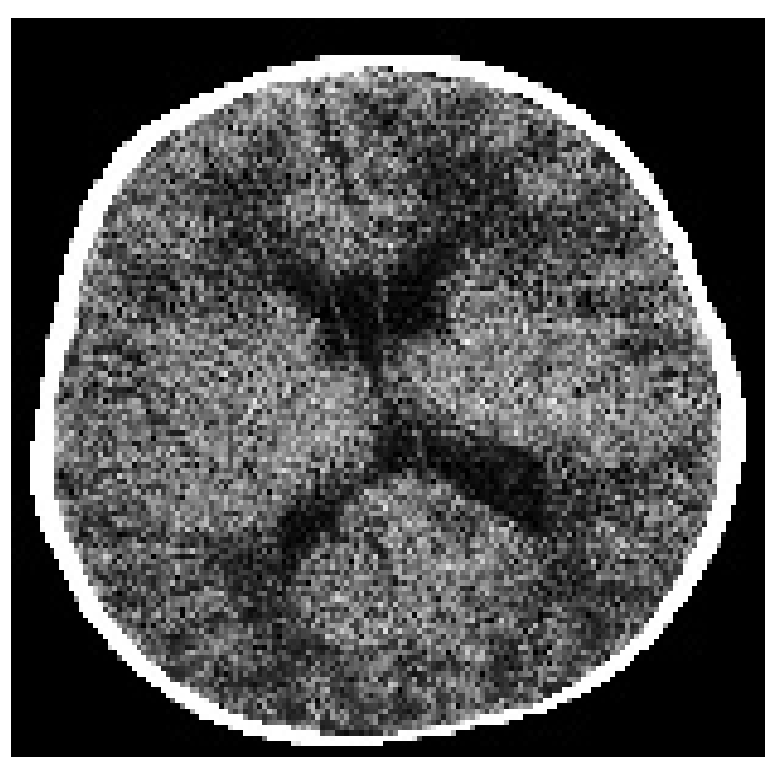

Figure 2. Head CT of Case 1 demonstrating resolution of cavum vergae with residual cavum septum pellucidum. Note the interval decrease in ventricular size.

not statistical evidence of such relationships (4).

Cavum vergae was first described by the Italian anatomist Andrea Verga in the 1800's. This "sixth" ventricle begins to develop by the $20^{\text {th }}$ week of gestation and disappears normally by two months of age (5). This cavity lies directly posterior to the cavum septum pellucidum and inferior to the fornices. It is not clear whether the cavum vergae is an extension of the cavum septum pellucidum or a separate entity (3). If truly an extension of the cavum, it is thought that it forms in the same manner as described for the embryology of the cavum septum pellucidum above (4). A wide variety of abnormalities have been associated with cavum vergae including macrocephaly, delayed development, and electroencephologram abnormalities $(3,5,6)$. As with our Case 1, macrocephaly is an associated finding in patients with cavum vergae. Miller et al. (5) have reported 10 children with cavum vergae of which four had macrocephaly. Could transient obstruction of the foramina of Monro before the regression of these cavities that are seen primarily in infants lead to hydrocephalus and macrocephaly that should simply be watched as the mass effect and obstruction lessen with cystic regression? This mechanism has been posited by Gubbay et al. (1). In their series of three patients, two patients had resolution of their hydrocephalus following excision of both their cavum septum pellucidi and vergae cysts. Our cases both with IVH could also merely demonstrate patients with temporary hemorrhagic blockage of the normal cerebrospinal fluid pathways that with time cleared. Wester et al. (2) have reported expanding cysts (cava septi pellucidi et vergae) producing obstructive hydrocephalus. Shunting of 


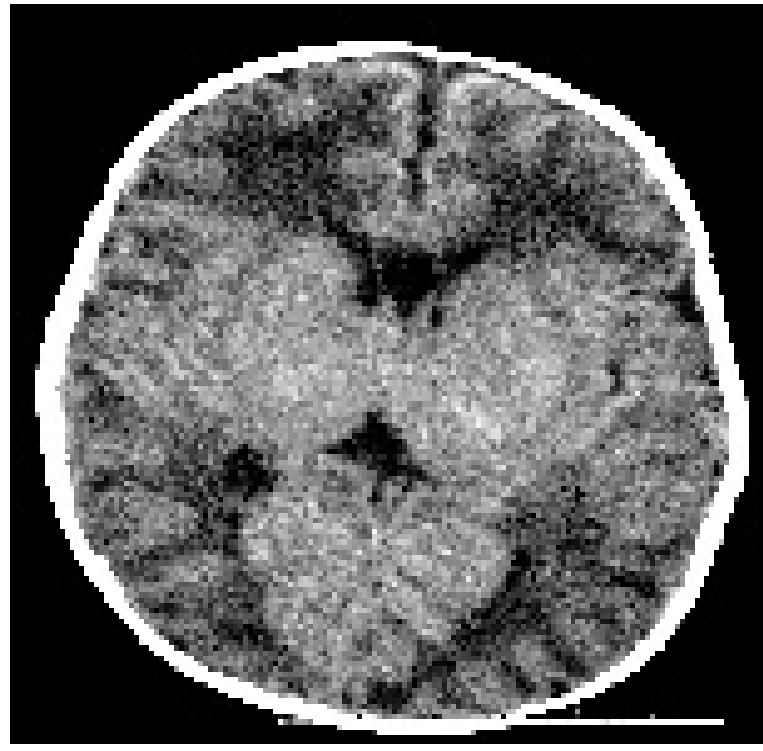

Figure 3. Head CT of Case 2 showing slightly increased ventricular size and cavum septum pellucidum.

the cysts effectively treated the hydrocephalus.

Cavum velum interpositum is a cavity that develops between the fornices above the third ventricle. This subarachnoid cistern an extension of the cisterna magna, was first described in the 1930's by Kruse and Schaetz (3). Persistence in children $1-10$ years old is approximately $30 \%$ (3). Few associations have been reported with the presence of this cavity. Interestingly, Supprian et al. (6) have reported monozygotic twins one with cavum vilum interpositum and psychosis and one with no cyst and normal mentation.

Normally, cavum vergae and cavum septi pellucidi are found together and communicate. Moreover, these cysts usually obliterate from posterior to anterior (7). Occasionally, cavum vergae have been found in isolation (7). Bodensteiner et al. (8) have concluded that cavum septi pellucidi may act as a marker for cerebral dysfunction manifested by neurodevelopmental delays while cavi vergae in isolation do not herald individuals at risk for mental delay.

The precise genetics of these intracranial cysts are unknown in humans. However, Wahlsten and Bulman-Fleming (9) have shown that corpus callosum dysmorphology is the result of more than one major genetic locus in inbred mouse strains. Although the genetics of schizophrenia are unclear, many have found an increase prevalence of cavum septum pellucidum in these patients (10).

\section{Conclusions}

Our case reports demonstrate identical twin brothers both with midline intracranial cysts, mild ventricular enlargement, and macrocephaly. With

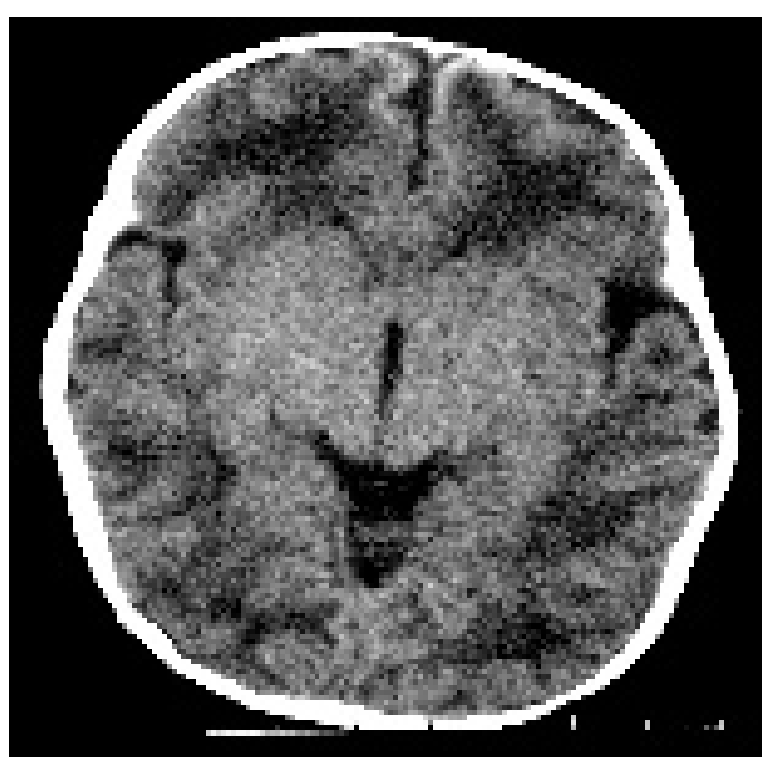

Figure 4. Head CT at last follow up of Case 2 showing near resolution of cavum septum pellucidum and decreased ventricular size.

each, the cysts were noted to obliterate with serial imaging and the ventricles to decrease in size. This coincided with the fall of each child's head circumference onto a normal head circumference curve. Although possibly coincidental, we believe these cases suggest that some infants with midline intracranial cysts and macrocephaly may represent transient episodes of raised intracranial pressure from mass effect that if merely observed, will dissipate with the collapse of the midline cavity. Some clinicians may also interpret macrocephaly and dilated ventricles in a patient with IVH as absolutely due to the IVH and prematurely shunt the child prior to excluding mass effect from a potential midline cyst. This knowledge should be entertained prior to the shunting or fenestration of midline cysts in infants with macrocephaly and mildly dilated ventricles. Further, our cases exemplify the usual benignity of these midline fluid collections and the natural history in these twins.

\section{References}

1 Gubbay SS, Vaughan R, Lekias JS. Intermittent hydrocephalus due to cysts of the septum pellucidum: a study of three cases. Clin Exp Neurol 1977; 14: $93-$ 99.

2 Wester K, Pedersen PH, Larsen JL, Waaler PE. Dynamic aspects of expanding cava septi pellucidi et vergae. Acta Neurochir 1990; 104: 147-150.

3 Rossitch E, Wilkins RH. Developmental midline intracranial cysts. In: Wilkins RH Rengachary SS (eds). Neurosurgery. New York: McGraw-Hill, 1985, pp 3707-3708.

4 Nakano S, Hojo H, Kataoka K, Yamasaki S. Age related incidence of cavum septi pellucidi and cavum vergae on $\mathrm{CT}$ scans of pediatric patients. J Comput 
Assist Tomogr 1981; 5: 348-349.

5 Miller ME, Kido D, Horner F. Cavum vergae. Association with neurologic abnormality and diagnosis by magnetic resonance imaging. Arch Neurol 1986; 43: 821-823.

6 Supprian T, Bengel D, Hofmann E, Fallgatter AJ, Franzek E. Cavum veli interpositi and psychotic disorder in a monocygotic twin. Eur Arch Psychiatry Clin Neurosci 2000; 250: 76-78.

7 Auer RN, Gilbert JJ. Cavum vergae without cavum septi pellucidi. Arch Pathol Lab Med 1982; 106: 462463.
8 Bodensteiner JB, Schaefer GB, Craft JM. Cavum septi pellucidi and cavum vergae in normal and developmentally delayed populations. J Child Neurol 1998; 13: 120-121.

9 Wahlsten D, Bulman-Fleming B. Retarded growth of the medial septum: a major gene effect in acallosal mice. Brain Res Dev Brain Res 1994; 18: 203-214.

10 Rajarethinam R, Miedler J, DeQuardo J, et al. Prevalence of cavum septum pellucidum in schizophrenia studied with MRI. Schizophr Res 2001; 48: 201-205. 